\title{
DIREITO E SAÚDE MENTAL DE PESSOAS FÍSICAS E JURÍDICAS
}

\section{LAW AND MENTAL HEALTH TO PERSON INDIVIDUAL AND COMPANIES.}

\author{
Penha, Nilton* \\ Inocente, Julieta J** \\ Groisman, Sonia**
}

\section{RESUMO}

Oobjetivo do presente trabalho foi levar ao conhecimento da comunidade científica uma revisão bibliográfica percebida ao longo da carreira acadêmica de um dos autores onde a personalidade física presente em coordenadores de alguns cursos de especialização em Odontologia é transmitida à personalidade jurídica tanto em instituições públicas quanto em privadas. A Legislação vigente, diferenças de personalidades físicas e jurídicas, transtornos mentais e de personalidade são explicitados, além de se projetar algumas possibilidades de acometimentos na medicação, os autores também questionaram a o fechamento de hospitais. Foi usada metodologia exploratória, através de palavras-chave no portal Capes e Scielo, com os descritores: Direito Administrativo • Saúde Mental - Ensino Odontológico • Políticas públicas de saúde; além de revistas e jornais virtuais. Concluiu-se que a falta de conhecimento em direito por parte dos docentes prejudica o processo de ensino e aprendizagem dos alunos. Existe, em alguns casos, o descaso contratual, pela falta de dissociação pessoal e institucional onde docentes e discentes se inserem, podendo este ser repassado num processo cíclico onde aprendidos e ensinados podem fazer parte de um sistema imutável. Existe a necessidade da revisão dos valores na metodologia de ensino odontológico para que transtornos de personalidade física não sejam perpetuados em pessoas jurídicas e assim não haja prejuízo e judicialização de ações por parte dos que têm noção de diretos e deveres como regras básicas de convívio social.

DESCRITORES: Direito administrativo • Saúde mental • Ensino odontológico • Políticas públicas de saúde

\section{ABSTRACT}

The aim of this study was to inform the scientific community through literature review, along the academic career of one of the authors where physical personality of some coordinated specialization courses of dentistry is transmitted to the legal personality, both in public and private institutions. The current legislation, differences in physical and legal personalities, mental and personality disorders are explained, in addition to design some bouts of possibilities in medication, the authors also questioned the closure of hospitals. An exploratory methodology was used through key words in the CAPES and Scielo website, with the following keywords: Administrative Law $\bullet$ Mental Health • Dental Education • Public health policies; as well as magazines and online newspapers. It concludes that the lack of knowledge in law by teachers, weaken the teaching and learning process of students, there are in some cases, the contractual carelessness and lack of differentiation personal and institutional where teachers and students are engaged. This may being passed in a cyclic process where learned and taught may be part of an unchanging system. There is the need to review the values in dental teaching methodology for those personality disorders do not perpetuate in persons and corporations, that there may prejudice those who has the notion of law and duties as basic rules of social life.

DESCRIPTORS: • Administrative law • Mental health • Dental education • Public health policies

\footnotetext{
* Cirurgião-Dentista, Especialista em Direito e Saúde pela ENSP/FIOCRUZ, Especialista em Periodontia pela Faculdade de Odon-tologia da UVA, Especialista em Saúde Coletiva pela Faculdade de Odontologia da UFRJ e Mestre em Clínica Odontológica pela Faculdade de Odontologia da UFF.

** Cirurgiã-dentista, Mestre em Psicologia "Saúde e Trabalho", Doutora em Psicologia, pela Universidade de Bordeaux 2. Especialista em Disfunção Temporomandibular e Dor Orofacial pela Associação Brasileira de Disfunção.

*** Professora Associada da Faculdade de Odontologia da Universidade Federal do Rio de Janeiro (UFRJ).
} 


\section{N T R O D UÇ Ã O}

Para conseguirmos orientar corretamente o objetivo deste artigo, iremos começar com um breve histórico da saúde mental no Brasil, assim como com dados epidemiológicos e sua classificação no Cadastro Internacional de Doenças. Em seguida, conceituaremos as definições de pessoa física e jurídics do ponto de vista das ciências sociais e, ainda, passaremos a discutir o caráter de personalidade física e jurídica, seu impacto sobre o ensino odontológico e apresentar considerações sobre possibilidades de tratamento.

Saúde mental no Brasil e Transtornos de Personalidade Antissocial

Para Guimarães et al. ${ }^{1}$ (2010), o primeiro aparato legal no Brasil voltado à pessoa com transtorno mental, que faz menção ao ser humano, foi aprovado após a promulgação da Constituição Federal de 19342, pelo Decreto $n^{\circ} 24.559 / 34$, que, ao dispor sobre a assistência e proteção individual, bem como sobre os bens dos psicopatas, considerava loucos os menores, os anormais, os toxicômanos, os intoxicados habituais e os indivíduos suspeitos incapazes de exercer pessoalmente os atos da vida civil ${ }^{3}$.

Ainda para os autores acima, na década de 1980 foi instituída a Reforma Psiquiátrica Brasileira pela Lei $n^{0} 10.216 / 01$, que dispõe sobre a proteção e os direitos das pessoas com transtorno mental e redireciona a assistência em saúde mental ${ }^{4}$.

Em novembro de 1991 foi promulgada a Portaria $n^{\circ}$. 189, que propôs a ampliação significativa na oferta de serviços e procedimentos em saúde mental. No ano seguinte, a Portaria $n^{\circ} 224$, além de complementar a Portaria $n^{\circ} 189$, tornou-se referência para o processo de transformação do modelo de atenção à saúde mental no país, uma vez que propunha o atendimento em unidades básicas, ambulatórios, NAPS/CAPS, HD, unidades de internação e de urgência psiquiátrica em hospitais gerais e especializados, cujas atividades deveriam ser desenvolvidas por uma equipe multiprofissional ${ }^{5}$.

Por meio da Portaria $n^{\circ} 145 / 94$, ficou estabelecido que a vistoria da assistência à saúde mental nos estabelecimentos credenciados deveria ser realizada por grupos compostos de representantes de gestores, usuários, familiares, prestadores de serviços e associações de profissionais de saúde. Os hospitais psiquiátricos deveriam ser priorizados e as escolhas poderiam ser a partir de amostras aleatórias, denúncias ou solicitações. Quando constatadas anormalidades nos estabelecimentos durante as vistorias, os relatórios das irregularidades encontradas seriam emitidos e as respectivas sanções aplicadas.

Mediante a Portaria $n^{\circ} 147 / 94$, foi previsto que cada instituição psiquiátrica precisaria estabelecer um projeto terapêutico com ações executadas por equipe multiprofissional e adequadas à característica da clientela desde a admissão até a alta do paciente, bem como sistemas de referência e contrarreferência, que garantam a continuidade do tratamento após a alta hospitalar.

Em 6 de abril de 2001 foi sancionada a Lei $n^{\circ} 10.216$, ou "Lei da Reforma Psiquiátrica Brasileira", como é conhecida. Essa reforma é aqui entendida como um processo complexo político e social caracterizado por atores, instituições e outras forças, que incidem nos níveis federal, estadual e municipal, nas universidades, no mercado dos serviços de saúde, nos conselhos profissionais, nas associações de pessoas com transtorno mental e de familiares, nos movimentos sociais, no imaginário social e na opinião pública. Ainda em 2001, foi aprovado, por meio do Decreto $n^{\circ}$ 3.956, o texto da Convenção Interamericana para a "Eliminação de todas as formas de discriminação contra as pessoas portadoras de deficiência", que inclui a restrição mental como forma de deficiência. O texto afirma que as pessoas com deficiência têm os mesmos direitos e liberdades inerentes ao ser humano e estabelece medidas para eliminar a discriminação contra essas pessoas. Essas medidas incluem o fornecimento de serviços, bens, instalações, programas e atividades, visando à plena integração à sociedade, garantia de melhor nível de independência e qualidade de vida pela detecção, tratamento, reabilitação, educação e formação ocupacional e sensibilização da população.
PENHA N

INOCENTE, JJ

GROISMAN S

DIREITO E SAÚdE

MENTAL DE

PESSOAS FÍSICAS

E JURÍDICAS

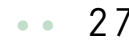

REV, ODONTOL.

UNIV. CID. SÃO

PAULO

$2015 ; 27(1): 26$ -

32 , JAN-ABR 
PENHA N

INOCENTE, JJ

GROISMAN $S$

DIREITO E SAÚDE

MENTAL DE

PESSOAS FÍSICAS

E JURÍDICAS

28

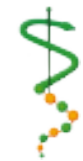

REV. ODONTOL.

UNIV. CID, SÃO

PAULO

$2015 ; 27(1): 26-$

32, JAN-ABR:
Em notícia retirada de um Sítio da Internet $^{6}(2013)$, a estimativa é que no Brasil haja 23 milhões de pessoas com distúrbios mentais sendo, destes, 5 milhões em níveis moderados e graves.

$\mathrm{Na}$ revista Cadernos de Saúde Públi$\mathrm{Ca}^{7}$, pesquisadores da Escola Nacional de Saúde Pública (Ensp/Fiocruz), em parceria com outras instituições, investigaram a taxa de transtornos mentais comuns (como depressão e ansiedade) e suas associações com características sociodemográficas apresentadas na atenção primária de 27 unidades de saúde da família de quatro capitais brasileiras. Os resultados apontaram taxas maiores que $50 \%$ nas cidades analisadas: 51,9\% no Rio de Janeiro, 53,3\% em São Paulo, 64,3\% em Fortaleza e 57,7\% em Porto Alegre.

De acordo com a Associação Americana de Psiquiatria, existe o Manual Diagnóstico e Estatístico de Transtornos Mentais (DSM-IV-TR). Nele é descrito o Transtorno de Personalidade Antissocial, popularmente chamado de psicopatia e/ou sociopatia e é descrito no site do DATASUS ${ }^{8}$ com os códigos de F60-F69 - transtornos da personalidade e do comportamento do adulto. Esse agrupamento compreende diversos estados e tipos de comportamento clinicamente significativos que tendem a persistir e são a expressão característica da maneira de viver do indivíduo e de seu modo de estabelecer relações consigo próprio e com os outros. Alguns desses estados e tipos de comportamento aparecem precocemente durante o desenvolvimento individual sob a influência conjunta de fatores constitucionais e sociais, enquanto outros são adquiridos mais tardiamente durante a vida. Os transtornos específicos da personalidade (F60.), os transtornos mistos e outros transtornos da personalidade (F61.-), e as modificações duradouras da personalidade (F62.-), representam modalidades de comportamento profundamente enraizadas e duradouras, que se manifestam sob a forma de reações inflexíveis a situações pessoais e sociais de natureza muito variada. Eles representam desvios extremos ou significativos das percepções, dos pensamentos, das sensações e particularmente das relações com os outros em relação àque- las de um indivíduo médio de uma dada cultura. Tais tipos de comportamento são geralmente estáveis e englobam múltiplos domínios do comportamento e do funcionamento psicológico. Frequentemente estão associados a sofrimento subjetivo e a comprometimento de intensidade variável do desempenho social.

Para citar alguns desses transtornos, seguem:

- F60 Transtornos específicos da personalidade

- F60.0 Personalidade paranoica

- F60.1 Personalidade esquizoide

- F60.2 Personalidade dissocial

- F60.3 Transtorno de personalidade com instabilidade emocional

- F60.4 Personalidade histriônica

- F60.5 Personalidade anancástica

- F60.6 Personalidade ansiosa [esquiva]

- F60.7 Personalidade dependente

- F60.8 Outros transtornos específicos da personalidade

- F60.9 Transtorno não especificado da personalidade

- F61 Transtornos mistos da personalidade e outros transtornos da personalidade

- F62 Modificações duradouras da personalidade não atribuíveis a lesão ou doença cerebral

- F62.0 Modificação duradoura da personalidade após uma experiência catastrófica

- F62.1 Modificação duradoura da personalidade após doença psiquiátrica

- F62.8 Outras modificações duradouras da personalidade

- Personalidade caracterizada por uma síndrome álgica crônica

- F62.9 Modificação duradoura da personalidade, não especificada

- F63 Transtornos dos hábitos e dos impulsos

- F63.0 Jogo patológico

- F63.1 Piromania

- F63.2 Roubo patológico [cleptomania]

- F63.3 Tricotilomania

- F63.8 Outros transtornos dos hábitos e dos impulsos

- F63.9 Transtorno dos hábitos e im- 
pulsos, não especificado

- F64 Transtornos da identidade sexual

- F64.0 Transexualismo

- F64.1 Travestismo bivalente

- F64.2 Transtorno de identidade sexual na infância

- F64.8 Outros transtornos da identidade sexual

- F64.9 Transtorno não especificado da identidade sexual

- F65 Transtornos da preferência sexual

- F65.0 Fetichismo

- F65.1 Travestismo fetichista

- F65.2 Exibicionismo

- F65.3 Voyeurismo

- F65.4 Pedofilia

- F65.5 Sadomasoquismo

- F65.6 Transtornos múltiplos da preferência sexual

- F65.8 Outros transtornos da preferência sexual

- F65.9 Transtorno da preferência sexual, não especificado

- F66 Transtornos psicológicos e comportamentais associados ao desenvolvimento sexual e à sua orientação

- F66.0 Transtorno da maturação sexual

- F66.1 Orientação sexual egodistônica

- F66.2 Transtorno do relacionamento sexual

- F66.8 Outros transtornos do desenvolvimento psicossexual

- F66.9 Transtorno do desenvolvimento sexual, não especificado

- F68 Outros transtornos da personalidade e do comportamento do adulto

- F68.1 Produção deliberada ou simulação de sintomas ou de incapacidades, físicas ou psicológicas [transtorno fictício]

- F68.8 Outros transtornos especificados da personalidade e do comportamento do adulto

- F69 Transtorno da personalidade e do comportamento do adulto, não especificado

Conceito de Pessoas Físicas e Jurídicas
Para Miranda ${ }^{9}$ (1974) a pessoa jurídica, assim como a pessoa física, são construções da ordem jurídica, que lhes atribui direitos e obrigações. Em ambas está presente o suporte fático em que se alicerça o direito, sendo tão somente distintas em termos de caracterização e sendo anódina a discussão se são reais, visto que a realidade é algo dado como resolvido quando se adentra o mundo jurídico, que, repita-se, estriba-se em substratos fáticos ${ }^{9}$. A pessoa jurídica é tão oriunda do mundo fático quanto a pessoa física, residindo a distinção em que a primeira é produto da criação do homem, enquanto a segunda é fruto da natureza, porém cabendo ao direito nos dois casos reconhecê-las e protegê-las9.

Ainda conforme Miranda ${ }^{9}$ (1974), ser pessoa é a possibilidade de ter direitos e esta possibilidade, de per si, é direito da personalidade. Tanto a pessoa física, quanto a pessoa jurídica, são criações do direito, que, com base em suporte fático, dá-Ihes capacidade de direito.

Segundo Bueno ${ }^{10}$ (2014), basicamente, todo ser humano é uma pessoa física e as empresas são pessoas jurídicas. No Código Civil, existem muitas diferenças entre os dois termos, tanto sobre a definição quanto em relação a direitos e deveres. Todo mundo é considerado Pessoa Física ao nascer, mesmo que não tenha Cadastro de Pessoa Física, o cadastro na Receita Federal. Já a Pessoa Jurídica é um conjunto de pessoas ou bens criado de acordo com a lei e com uma finalidade - que pode ser administração, prestação de serviços, produção ou comercialização de produtos. E ainda sempre há uma pessoa física responsável pela jurídica e, em alguns casos, o indivíduo poderá responder por problemas na empresa.

\section{MÉTODOS}

Esta pesquisa utilizou metodologia exploratória, através das palavras-chave nos últimos 10 anos utilizadas no portal Capes e Scielo, com os descritores: Direito Administrativo - Saúde Mental • Ensino Odontológico - Políticas públicas de saúde; também foram utilizadas revistas, jornais virtuais e juntamente foram relata-
PENHA N

INOCENTE, JJ

GROISMAN S

DIREITO E SAÚdE MENTAL DE

PESSOAS FÍSICAS

E JURÍDICAS 
PENHA N

INOCENTE, JJ

GROISMAN S

DIREITO E SAÚDE:

MENTAL DE

PESSOAS FÍSICAS

E JURÍDICAS

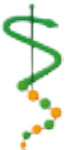

REV. ODONTOL

UNIV. CID. SÃO

PAULO

$2015 ; 27(1): 26-$

$32, J A N-A B R$ das experiências pessoais do autor principal ao longo de três especializações, um mestrado concluído e uma especialização em curso, relatando atitudes institucionais passíveis de ações judiciais e levando em consideração o direito e o ensino em saúde.

\section{CONSIDERAÇÕES SOBRE O DIREITO}

Para Nohara ${ }^{11}$ (2014), Direito Administrativo é o ramo do direito público que trata de princípios e regras que disciplinam a função administrativa e que abrange entes, órgãos, agentes e atividades desempenhadas pela Administração na consecução do interesse público.

Podemos citar as relações de contrato, segundo Santana ${ }^{12}$ (2011); no Direito existem alguns princípios que podemos destacar como base fundamental para estabelecer um equilíbrio justo na elaboração de um contrato. As partes são livres para estipular o formalismo do contrato, desde que não seja de uma forma ilícita, sendo que uma parte lhe oferece uma proposta e a outra a aceita e, com o aceite, estará formado o contrato. Ainda consiste no poder das partes de estipular livremente, mediante acordo de vontades, a disciplina de seus interesses envolvendo, além de tudo, a liberdade de contratar, de escolher ou outro contratante e de fixar o conteúdo do contrato, limitadas pelo princípio da função social do contrato, pelas normas de ordem pública, pelos bons Costumes e pela revisão judicial dos contratos.

Para Diniz ${ }^{13}$ (2008), diante do Princípio da Obrigatoriedade da Convenção, as estipulações feitas no contrato deverão ser fielmente cumpridas, sob pena de execução patrimonial contra o inadimplente. $\mathrm{O}$ ato negocial, por ser uma norma jurídica, constituindo lei entre as partes é intangível, a menos que ambas as partes o rescindam voluntariamente, ou haja a escusa por caso fortuito ou força maior (CC, Art. 393, parágrafo único), de tal sorte que não se poderá alterar seu conteúdo, nem mesmo judicialmente.

\section{DESENVOLVIMENTO E DISCUSSÃO}

Como se pôde ver anteriormente, a população brasileira, em 2015, segundo o $\operatorname{IBGE}^{14}$ (2015), é estimada em 203 mi-
Ihões de habitantes, uma vez existindo 23 milhões de pessoas com algum nível de distúrbio(s) mental(is), isto equivale a $11.3 \%$ da população total brasileira, um número alto, pois, vendo de uma outra maneira, a cada 10 pessoas, ao menos uma tem problema mental e este pode ter sido desenvolvido precoce ou tardiamente. Também se pôde ver que na Ata da $238^{\circ}$ da Reunião Ordinária do Conselho Nacional de Saúde ${ }^{15}$ nos dias 9 e 10 de outubro de 2012, este recomendou ao Ministério da Saúde em seus primeiros itens que:

1- Acelere o ritmo de fechamento de leitos em Hospitais Psiquiátricos e da construção de redes diversificadas e territorizadas;

1.1- Apresente o plano de fechamento de leitos para o período do próximo PPA (2012-2015) com metas claras da redução progressiva de leitos hospitalares psiquiátricos;

1.2- Defina, em curto prazo, o fim do repasse de recursos para os hospitais psiquiátricos que tenham mais de 400 leitos;

1.3- Solicite, e pactuação, com os Estados de construção do plano de metas de fechamento de leitos psiquiátricos/ano;

1.4- Defina os prazos específicos para adequação dos Hospitais Psiquiátricos Públicos às normas e diretrizes da Reforma Psiquiátrica e para constituição das Redes Psicossociais;

1.5- Não repasse de recursos aos Hospitais Psiquiátricos que internem crianças ou adolescentes. A internação de crianças requer cuidado e acolhimento nos espaços territoriais e nos dispositivos adequados;

1.6- Incentive a implantação de CAPS III, como mecanismo essencial à efetiva desativação de leitos em hospitais psiquiátricos;

1.7- Aumente as Residências Terapêuticas e o número dos usuários do Programa de Volta para a Casa;

Considerando o fechamento dos Hospitais Psiquiátricos para a regionalização do tratamento e a dificuldade de se ofertar terapias adequadas a mais de $11 \%$ da população brasileira, é possível ressaltar que muitas dessas pessoas, antes em hospitais, agora se veem livres e em convívio social, e a própria constituição exemplifica o di- 
reito de ir e vir, mas, em contrapartida, recentemente vimos em uma notícia recente que, ao voltar da África e sob o risco de ter contraído lá o Ebola ${ }^{16}$, uma pessoa ficou em quarentena até que fosse dado o diagnóstico definitivo, ou seja, sua liberdade foi restringida.

É interessante como as doenças, sejam contagiosas ou contagiantes, assim como são os casos do Ebola e do convívio social com pessoas com problemas mentais, estão sujeitas a pontos de vista diferentes, quando falamos em saúde pública, pois, de um lado, a liberdade de ir e vir é arraigada e, de outro, um direito de tratamento institucional adequado e por profissionais capacitados também é posto como obsoleto e há uma recomendação para o fechamento desses hospitais psiquiátricos, deixando livre ("mesmo que em risco de vida") quem antes estava em tratamento. Não é a intenção deste artigo comentar sobre o tipo, efetividade e eficácia dos tratamentos propostos. Mas somos levados a crer que deveria ter sido feita uma vigilância e não cerceamento do direito a tratamento de saúde mental de que uns gozavam.

Uma vez citado o fechamento dos hospitais psiquiátricos, em vista da grande quantidade dos que necessitam de tratamento e estão soltos, livres e, muitos deles, desprovidos de um estado de consciência de modo a procurarem tratamento e onde se tratarem adequadamente, pois a rede foi alterada, é válido afirmar que qualquer um de nós somos sujeitos a desenvolver algum tipo de distúrbio neurológico (neuroses) passível de tratamento, desde o nascimento e ao longo de nossas vidas.

\section{CONCLUSÃO}

Se conseguirmos imaginar que $10 \%$ da população possui algum problema mental e que tal problema pode ser desenvolvido ao longo dos anos, talvez o convívio não o torne contagioso, mas sim se torne contagiante, pois, desde o desenvolvimento da linguagem e das formas de expressão, o ser humano procura a coexistência social e, apesar de a "loucura estar à solta", ainda existe tratamento; seja ele à base de remédios tarja preta para os indivíduos (pessoa física) ou por meio de medicação jurídica para as instituições (pessoa jurídica). Mas, no final de contas, ambas as medicações podem vir a ser bem-vindas.

\section{Considerações finais dissociadas do} artigo

Em tal artigo é válido comentar sobre a carreira acadêmica do autor principal no decorrer de sua graduação, atualização, três especializações, um mestrado cursado e uma especialização em andamento, pois, ao longo desse período, foi possível verificar a diferença de ideologias e até de alteração de humor em alguns docentes. Tais alterações e diferenças motivaram a esta publicação, devido aos estresses da vida universitária, docentes podem já ter ou estar desenvolvendo problemas neurológicos ou psiquiátricos, sendo estes repassados da pessoa física para a própria instituição de ensino (pessoa jurídica). Apesar de existirem exceções, as mesmas não podem prejudicar os alunos de especialização, tão pouco as próprias universidades em questão.
PENHA N

INOCENTE, JJ

GROISMAN S

DIREITO E SAÚde MENTAL DE

PESSOAS FÍSICAS

E JURÍDICAS

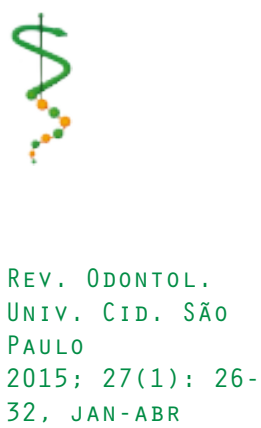


INOCENTE, JJ

GROISMAN S

DIREITO E SAÚDE:

MENTAL DE

PESSOAS FÍSICAS

E JURÍDICAS

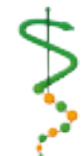

REV, ODONTOL,

UNIV, CID, SÃO

PAULO

$2015 ; 27(1): 26-$

$32, J A N-A B R$

REFERÊNCIAS

1. Guimarães AN, Fogaça MM, Borba LO, Paes MR, Larocca LM, Maftum MA. O tratamento ao portador de transtorno mental: um diálogo com a legislação federal brasileira (19352001). Texto contexto - enferm 2010 jun;19(2):274-82.

2. Canabraval DS, Souza TS, Fogaça MM, Guimarães AN, Borille DC, Villela JC, et al. Tratamento em saúde mental: estudo documental da legislação federal do surgimento do Brasil até 1934. Rev Eletr Enf 2010 12(1):170-6.

3. Brasil. Decreto n ${ }^{\circ} 24.559$, de 03 de juIho de 1934: dispõe sobre a profilaxia mental, a assistência e proteção à pessoa e aos bens dos psicopatas, a fiscalização dos serviços psiquiátricos e dá outras providências. Brasilia: Câmara dos Deputados; 1934.

4. Brasil. Lei $n^{0} 10.216$, de 6 de abril de 2001: dispõe sobre a proteção e os direitos das pessoas portadoras de transtornos mentais e redireciona o modelo assistencial em saúde mental. Brasilia: Diário Oficial da União; 2001.

5. Borges CF, Baptista TWF. O modelo assistencial em saúde mental no Brasil: a trajetória da construção política de 1990 a 2004. Cad Saúde Pública 2008 fev;24(2):456-68.

6. Walbert A. Saúde mental: transtornos atingem cerca de 23 milhões de brasileiros. 2013 [Acesso em: 18 de maio de 2014]. Disponível em: http://www.ebc.com.br/noticias/saude/2013/05/saude-mental-em-numeros-cerca-de-23-milhoes-de-brasileiros-passam-por

7. Moehlecke R. Pesquisa mostra alta incidência de transtornos mentais na população de capitais brasileiras. Rio de Janeiro: FIOCRUZ; 2014 [Acesso em Disponível em: http://portal.fiocruz. br/pt-br/content/pesquisa-mostra-alta-incidencia-de-transtornos-mentais-na-populacao-de-quatro-capitais.
8. DataSUS. F60-F69 Transtornos da personalidade e do comportamento do adulto. 2015 [Acesso em: 23 de maio de 2014]. Disponível em: http:// www.datasus.gov.br/cid10/V2008/ WebHelp/f60_f69.htm

9. Miranda P. Tratado de direito privado: parte geral. 4. ed. São Paulo Revista dos Tribunais; 1974.

10. Bueno K. Qual a diferença entre pessoa física e jurídica?[2014]; 129. Disponível em: http://mundoestranho. abril.com.br/materia/qual-a-diferenca-entre-pessoa-fisica-e-juridica.

11. Nohara IP. Direito administrativo. 4. ed. São Paulo: Atlas; 2014.

12. Santana A. Princípios fundamentais do direito contratual. Rev Npi/Fmr [Periódico on-line].2011; 5(1). Disponível em: http://www.fmr.edu.br/npi/ npi_direito_contratual.pdf.

13. Diniz MH. Curso de direito civil brasileiro: teria das obrigações contratuais e extracontratuais. 24. ed. São Paulo: Saraiva; 2008.

14. IBGE. Projeção da população do Brasil e das Unidades da Federação. 2015 [Acesso em: 23 de maio de 2014]. Disponível em: http://www.ibge.gov. br/apps/populacao/projecao/

15. Brasil. Ata da $238^{\circ}$ reunião ordinária do conselho nacional de saúde nos dias 9 e 10 de outubro de 2012. 2012 [Acesso em Disponível em: conselho. saude.gov.br/recomendacoes/2012/ Reco023.doc.

16. Carvalho J. Primeiro exame de africano internado no Rio descarta ebola. 2014 [Acesso em: 02 de junho de 2014]. Disponível em: http://oglobo. globo.com/sociedade/saude/primeiro-exame-de-africano-internado-no-rio-descarta-ebola-14218974.

RECEBIDO EM 18/05/2015

ACEITO EM 22/05/2015 